\title{
Strategies to reduce social exclusion for people with mental health problems
}

\author{
Liz Sayce and Laurence Measey
}

The Royal College of Psychiatrists and MIND are both engaged in specific initiatives to reduce stigma and discrimination faced by people with mental health problems. MIND launched its 'Respect' campaign in 1997 (MIND, 1997), the College its 'Changing Minds: Every Family in the Land campaign in 1998. To achieve gains in 'social inclusion', public education campaigns will need to be complemented by policy and practice changes. This editorial examines, from the standpoint of both organisations, what such changes might involve.

\section{The experience of exclusion}

The UK Government is committed to tackling social exclusion. On virtually any indicator of 'social exclusion', people with long-term or intermittent mental health problems score highly.

The Labour Force Survey 1997/8 (Office of National Statistics, 1998) showed that persons with a history of psychiatric disorder do badly when compared with other disabled persons in returning to work. Only $13 \%$ are working, as compared with over a third of disabled people generally. Yet this is not accounted for by inability to work: a diagnosis of mental illness is not a reliable predictor of work capacity (Anthony et al, 1995), and evidence is accumulating that, with intensive and flexible support where necessary, unemployment rates can be significantly reduced (Bond et al, 1997).

Access to services from life insurance to holidays, mortgages to general health care, can be placed in jeopardy by a diagnosis of mental illness (Read \& Baker, 1996; Sayce, 1999). For example. users of mental health services frequently report that they receive late or insufficient tests for physical complaints, often because complaints are interpreted initially as a manifestation of psychiatric illness (Read \& Baker, 1996). Lawrie et al (1998; presentation to Royal College of Psychiatrists Annual Meeting, Belfast, further details available from the author upon request) additionally report that general practitioners responding to case vignettes about people with schizophrenia were less happy to have them on their lists than other patients, and more concerned about violence and any child's welfare. Patients correspondingly reported negative attitudes towards them from doctors. These findings are of particular concern given high rates of coronary heart disease and other major illnesses among people with schizophrenia, and standardised mortality rates running at two and a half times the average (Department of Health, 1994).

People with mental health problems can also be excluded from geographical communities and access to housing. Nimby ('not in my backyard') campaigns have increased during the 1990s, often resulting in delays or re-siting of mental health projects, or even attacks on residents or staff (Repper et al, 1997).

Unsurprisingly, many people choose, where they can, to hide their psychiatric status. A national American survey of people with serious mental illness (mainly schizophrenia, bipolar disorder and major depression) found that four out of five respondents worried that others would view them unfavourably if their illness was disclosed and therefore avoided telling them (Wahl, 1997). A Staten Island study found that a quarter revealed their condition only to close family members and 7\% did not even tell them (Wahl, 1995). Link et al (1997) found that $75 \%$ of seriously mentally ill people would not tell a prospective employer, and $60 \%$ would not apply for a job if they feared an employer would not hire someone who had been in psychiatric hospital. Maintaining secrets can create its own pressures (Faulkner \& Sayce, 1997) and fear of rejection can prompt social withdrawal (Link et al, 1997).

\section{Creating opportunities for 'inclusion'}

Government initiatives offer some opportunities to tackle this exclusion, and the prejudice that often accompanies it: for example, through the New Deal for disabled people, the Disability 
EDITORIAL

Rights Commission, Lifelong Learning, Education and Health Action Zones (Sayce \& Morris 1999). The Government has not yet placed any explicit priority on reducing exclusion 'on menta health grounds'. Its Social Exclusion unit has focused on street homelessness, 'problem' estates, school exclusions and teenage pregnancy.

Available evidence suggests that the most effective way to address exclusion is through a mixture of legal reform, to set a benchmark of what society considers acceptable; work with the media, film and other educational routes to reframe' current discourse; and local initiatives to encourage access for service users to a wide range of opportunities thereby demonstrating that people with mental health problems represent 'contributors' not just 'burdens', and increasing familiarisation between service users and others in the variety of communities in which they engage (Sayce, 1998). National educational campaigns alone are likely to be less effective than local approaches (Wolff et al $1996 a$ ).

\section{Legal reform}

The Disability Discrimination Act 1995, while offering some small protection for people with mental health problems, is constrained by very narrow definitions of disability and lack of an enforcement mechanism. To date there have been few cases taken concerning discrimination on mental health grounds. The MIND 'Respect' campaign has prioritised taking test cases under this law; educating employers and users about duties, rights and good practice; and promoting legal change with the Government. Through representation on the Disability Rights Task Force. MIND and other disability organisations have influenced proposals for a Disability Rights Commission, similar to the Equal Opportunities Commission, which would explicitly cover psychiatric as well as physical and sensory impair ments. A majority of commissioners are proposed to be 'disabled', potentially including people with mental health problems.

\section{Public education}

Influencing public attitudes in this area is complex, influencing behaviour even more so (Sayce, 1999). Public knowledge is low, mental illness being often confused with mental handicap (Wolff et al, 1996b). Mental illness is often conflated with crime - a link that is constantly reinforced by cinema and the media. Attitude surveys tend to find tolerant attitudes coinciding with resistance to having people with mental illness living nearby, marrying one's daughter or otherwise getting too close (Repper \& Brooker, 1996). On the other hand, Wolff et al (1996a) identify a 'pool of goodwill' that can be tapped at local level.

The College ('Every family in the land: recommendations for the implementation of a five-year strategy: 1998-2003': available upon request from the External Affairs and Information Services Department of the Royal College of Psychiatrists, 17 Belgrave Square, London SW 1X $8 \mathrm{PG}$ ) plans to promote better understanding of mental illness by producing information leaflets and a series of educational modules to inform the medical profession, educationalists, employers and the media. MIND has worked to promote a range of stories in the media that illuminate the different realities of people's lives, and to publicise the reality of discrimination. For example, MIND's two reports on discrimination received over $\mathbf{3 0 0}$ sympathetic mentions in national and local media (Read \& Baker, 1996; Repper et al, 1997).

\section{Local initiatives}

Many clinicians, voluntary organisations and user groups across the country are involved in projects that help break down barriers to inclusion. For example, clinicians working in liaison psychiatry can be highly influential with other doctors in ensuring that people with serious mental health problems gain access to good-quality physical health care. Sensitive approaches to occupational health reporting can make a critical difference to people's chances of securing work. Some NHS trusts are acting as exemplars by introducing policies to debar employment discrimination, and provide a measure of supported employment for their own staff (Perkins et al, 1997). Voluntary organisations engage in supporting people to get involved in anything from sports events to religious activity. adult education to work (Repper et al, 1997). Supported employment initiatives generally are on the increase.

MIND has produced guidelines for local service providers on how to work constructively with local communities and how to prevent and tackle 'nimby' campaigns (Sayce \& Willmot, 1997), and it has run a national inquiry, "Creating Accepting Communities', to identify and promote good practice.

\section{Remaining challenges}

A Disability Rights Commission is to be set up. with powers to promote good practice among employers and providers of service, conduct investigations, and ensure disabled people have access to justice. It will only be effective for those disabled by psychiatric problems or history, if service users and professionals influence the new Commission. It will then be possible for the 
Commission to monitor discrimination and make recommendations for adequate protection from discriminatory practices. Without such representation disability will continue to be seen by the business world and general public in terms of wheelchair users and, possibly, those with sensory impairments. There is a huge need to promote success stories of making 'reasonable adjustments' enabling those with mental health problems to work; to support and advise employers; and to ensure the New Deal for disabled people succeeds in improving labour participation for mental health service users - who, after all, have the highest unemployment rate of all.

We also need the law to give more adequate protection from discrimination to those with mental health difficulties, and strong measures to break benefit disincentives. The Government's action in 1998 to extend the 'linking rule' for Incapacity Benefit, to enable people to try work with less fear of loss of income, was a welcome start: as was the 1998 commitment to tax credits. Also needed are reforms to the Disability Living Allowance so that it becomes an enabling benefit and a clearer and simpler system of making benefit claims which can be modified without loss of income as a person goes through rehabilitation and training processes toward full employment.

Finally, we need a complementary policy from the Department of Health, that recognises the full needs of persons with mental health problems by producing policy and guidelines that emphasise the importance of rehabilitation and actions for social inclusion. Through the National Service Framework for Mental Health and Local Health Improvement Plans there is an opportunity to ensure better collaborative work between health and local authorities to provide a comprehensive service that works to enhance the quality of life rather than response to illness alone. Furthermore by collaboration with the Department of Education and Employment targets could be set for health authorities, employment services and local employers to provide enhanced opportunities for training and employment. Such initiatives would lend themselves to measurable outcomes and audit.

The current policy emphasis on social inclusion provides opportunities for different agencies and sectors to work together, locally and nationally, to improve the chances of people with serious mental health problems to lead dignified lives. The two campaigns from the College of Psychiatrists and MIND both have the potential to contribute to this aim.

\section{References}

ANThony, W. A., Rogers, E. S., COHEN, M., et al (1995) Relationships between psychlatric symptomatology. work skills and future vocational performance. Psychiatric Services, 46, 353-357.

BOND, G. R., DRAKE, R. E., MUESER, K. T., et al (1997) An update on supported employment for people with severe mental illness. Psychiatric Services, 48, 335-346.

DEPARTMENT OF HEALTH (1994) Health of the Nation Key Area Handbook. Mental Illness (2nd edn). London: HMSO.

Faulkner, A. \& SAYCE, L. (1997) Disclosure, Open Mind 85. pp. 8-9. London: MIND.

LiNK. B. G., RAHAV, M., PHELAN, J. C., et al (1997) On stigma and its consequences: evidence from a longitudinal study of men with dual diagnosis of mental illness and substance abuse. Journal of Health and Social Behaviour, 38, 177-190.

MIND (1997) Respect. Time to End Discrimination on Mental Health Grounds. (Campaign leaflet). London: MIND.

OfFICE OF NATIONAL STATISTICS (1998) Labour Force Survey (1997/8). London: Office of National Statistics.

PERKINS, R. BUCKFIELD, R, \& CHOY, D. (1997) Access to employment: a supported employment project to enable mental health service users to obtain jobs within menta health teams. Journal of Mental Health. 6, 307-318.

READ, J. \& BAKER, S. (1996) Not Just Sticks and Stones. A Survey of the Stigma. Taboos and Discrimination Experienced by People with Mental Health Problems. London: MIND.

REPPER, J. \& BROOKER, C. (1996) A Review of Public Attitudes Towards Mental Health Facilities in the Community. Sheffield: Sheffield Centre for Health and Related Research.

-. SAYCE. L., STRONG, S., et al (1997) Tall Stories from the Back Yard. A Survey of 'Nimby' Opposition to Community Mental Health Facilities Experienced by Key Service Providers in England and Wales. London: MIND.

SAYCE. L. (1998) Stigma. discrimination and social exclusion: what's in a work? Journal of Mental Health, 7, 4.

- (1999) From Psychiatric Patient to Citizen. London: Macmillan (in press).

- \& Willmot, J. (1997) Gaining Respect: A Guide to Preventing and Tackling Community Opposition to Mental Health Services. London: MIND.

- \& MORRIS. D. (1999) Social Inclusion and Mental Health. London: MIND/NHS Executive (in press).

WAHL. O. F. (1995) Media Madness. Public Images of Mental Illness. New Brunswick: Rutgers University Press.

- (1997) Consumer Experience of Stigma. Results of a National Survey. Washington. DC: George Mason University.

Wolff, G.. Pathare. S.. Craig. T.. et al (1996a) Public education for community care. British Joumal of Psychiatry, 168, 441-447.

- - - . - et al (1996b) Community knowledge of mental illness and reaction to mentally ill people. British Journal of Psychiatry. 168. 191-198.

Liz Sayce wrote this editorial as Policy Director of MIND, she is now Director, Lambeth. Southwark and Lewisham Health Action Zone, London: and *Laurence Measey, Chairman, Rehabilitation and Social Psychiatry. The Caludon Centre, Clifford Bridge Road, Walsgrave, Coventry CV2 2TE

*Correspondence 